\title{
Effect of critical thickness on nanoconfined water fluidity: review, communication, and inspiration
}

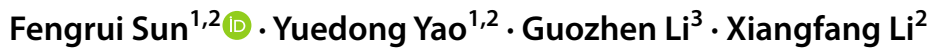

Received: 13 July 2018 / Accepted: 20 August 2018 / Published online: 25 August 2018

(c) The Author(s) 2018

\begin{abstract}
It is crucial to precisely estimate the water transport behaviors in shale formation. However, the present study on this subject is quite limited. A comprehensive literature review is conducted and some improvements are proposed. In this paper, an improved model is proposed to investigate the flow of water in nanopores of shale formation. First, a quadratic equation is proposed to build the relationship between water viscosity and contact angle. Then, the effect of critical thickness on water transport behaviors is discussed. Results show that: (a) the flow enhancement is smaller than 1 when the contact angle is smaller than $100^{\circ}$ due to energy barrier induced by strong hydrophilicity of the nanopore wall; (b) the flow enhancement becomes infinite when the contact angle is approaching $180^{\circ}$; and (c) the flow enhancement increases with decreasing of critical thickness, especially for hydrophilic nanopores (the contact angle is smaller than $120^{\circ}$ ) and nanopores with a relatively small diameter (smaller than $50 \mathrm{~nm}$ ).
\end{abstract}

Keywords Nanopores in shale $\cdot$ Water transport $\cdot$ Slip flow $\cdot$ Critical thickness $\cdot$ Contact angle

\section{Introduction}

With the increasing demand for energy and decreasing conventional resources, as well as the rapid development of technology, shale oil has gradually formed an upsurge (Monge et al. 2017; Tan and Barton 2017; Yu et al. 2018; Alfarge et al. 2018). The distribution and percolation characteristics of water in shale reservoirs are one of the key problems in the development of shale oil (Feng et al. 2018a,

Fengrui Sun

13126682711@163.com

Yuedong Yao

yaoyuedong@163.com

$\triangle$ Guozhen Li

guozhenli76@163.com

1 State Key Laboratory of Petroleum Resources and Prospecting, China University of Petroleum - Beijing, Beijing 102249, People's Republic of China

2 College of Petroleum Engineering, China University of Petroleum - Beijing, Beijing 102249, People's Republic of China

3 College of Mechanical and Transportation Engineering, China University of Petroleum - Beijing, Beijing 102249, People's Republic of China b; Zhang et al. 2017a, b). In fact, the understanding of water transport behavior in nanopores or nanotubes is crucial in different academic fields, as well as industry application, such as purification (Shannon et al. 2008), energy usage (Aricò et al. 2005; Sparreboom et al. 2009; Siria et al. 2013), pharmacy (Sanhai et al. 2008), and geoscience (Warner et al. 2012; Keranen et al. 2014). At present, theoretical and experimental researches tend to promote each other's development. With the rapid development of nano-manufacturing technology (Naguib et al. 2004; Lasne et al. 2008; Mirsaidov et al. 2012; Ortiz-Young et al. 2013; Huang et al. 2013; Chiavazzo et al. 2014), it lays the foundation for the verification of a new theoretical model (Holt et al. 2006; Karan et al. 2012; Surwade et al. 2015).

It has been pointed out by many researchers that the flow behaviors of nanoconfined water vary drastically from bulk water due to strong water-wall interactions induced by nanoscale transmission channel (Heuberger et al. 2001; Scatena et al. 2001; Werder et al. 2001; Levinger 2002; Rivera et al. 2002; Köfinger et al. 2008; Mashl et al. 2003; Liu et al. 2005a, b; Krott et al. 2015; Ma et al. 2015; Wu et al. 2017). With the discovery of new physical phenomena, theoretical models are in need to describe and estimate these new phenomena (Wu et al. 2017). At nanoscale, the Hagen-Poiseuille equation is no longer useful in estimating water flow 
rate in nanotubes. Experiments conducted by Majumder et al. (2005) and Holt et al. (2006) have discovered that the water transport rate in carbon nanotubes with diameters of $1.3-7.0 \mathrm{~nm}$ is $2-5$ orders of magnitude larger than the predicted results by the Hagen-Poiseuille equation. Further experiment conducted by Whitby et al. (2008) revealed that when the diameter of nanotube is up to $44 \mathrm{~nm}$, the water transport rate is only one order of magnitude higher than the predicted results by the Hagen-Poiseuille equation. One may find that the smaller the diameter of the nanotube, the greater the difference between experiments results and non-slip Hagen-Poiseuille's results. What is worth to mention is that these nanotubes are hydrophilic. Further studies discovered that the water transport rate is smaller than the predicted results by the Hagen-Poiseuille equation when the surface of nanotube shows hydrophobicity (Chan and Horn 1985; Heinbuch and Fischer 1989; Granick 1991; Thompson and Troian 1997). These new physics was then summarized into a theoretical model by Wu et al. (2017) who established a model to build the relationship between contact angle (wettability) and water transport rate in nanotubes.

While the interaction between nanopore wall and water plays a dominant role in water transport at nanoscale (Liu et al. 2005a, b; Whitby and Quirke 2007; Lorenz and Zewail 2014; Verweij et al. 2007; Nair et al. 2012), the continuum modeling method widely adopted in describing water flow in micropores is still useful for modeling of water transport in nanotubes with a diameter larger than $1.6 \mathrm{~nm}$ (Sparreboom et al. 2009; Wu et al. 2017; Striolo 2006; Nair et al. 2012). However, different from water transport in micropores, the governing physics of water transport in nanopores become various boundary conditions (slip flow or multilayer sticking), caused by wettability, and viscosity variation in nanopores, caused by strong interactions from nanopore wall (Monteiro et al. 2012; Falk et al. 2015; Klein and Kumacheva 1995; Neto et al. 2005). In this paper, an improved model was proposed based on Wu et al.'s work (2017). A new relationship between viscosity variation and contact angle is proposed. Then, a new flow enhancement model is developed based on the concept of critical thickness, which represents integrated wall properties of shale formation. This model is useful in analyzing water transport behaviors in nanopores of shale formation under various wall property conditions, which are reflected in the critical thickness.

\section{Transport mechanisms}

At present, a series of experiments and molecular dynamic simulations are conducted on water transport mechanisms in nanopores with various wall materials. However, some basic physics are still unknown or not well understood. Recently, some researchers tried to reveal the relationship between water transport rate and wettability in carbon nanotubes, and they have proposed analytical equations for transport rate calculation (Wu et al. 2017). While their work moves onestep forward, there are still many deficiencies waited to be modified and unknowns waited to be explored.

The previous works have revealed that the structural and dynamical properties of water in nanopores, especially water in the surface region, vary significantly from those of bulk water (Mashl et al. 2003; Liu et al. 2005a, b). Both experiments and molecular dynamic simulations have confirmed that the viscosity of water in nanopores is not a constant. The viscosity of water in the surface region is larger or smaller than that in the center of the nanopores due to strong interactions induced from the nanopore wall (Goertz et al. 2007; Campbell et al. 1996; Li et al. 2007). Besides, more importantly, the conventional assumption of non-slip flow at boundary condition is no longer applicable (Holt et al. 2006; Majumder et al. 2005; Neto et al. 2005; Cottin-Bizonne et al. 2003). It has been pointed out that the viscosity profile and slip flow are closely linked to a physical parameter: the ratio of the water-wall interaction to the water-water interaction (Krott et al. 2015; Wu et al. 2017; Granick et al. 2003). In fact, when the ratio is higher than 1 , the water in the surface region becomes ordered and a number of fluid layers are stick to the surface wall. This is because the interaction between nanopore wall and water is strong when the wall material is hydrophilic (Thompson and Robbins 1990). Further studies have confirmed that when the wall material is hydrophilic, generally, the viscosity of water in the surface region is higher than that of bulk water, and the non-slip boundary assumption is still in line with the reality (Wu et al. 2017; Heinbuch and Fischer 1989; Raviv et al. 2001; Feibelman 2013). When the wall material is med-wetting, the non-slip boundary assumption still holds in general, and the viscosity of water in the vicinity of the wall decreases with increasing contact angle (Joseph and Aluru 2008). However, when the nanopore wall material becomes hydrophobic, water is detected to slip directly on the wall and the non-slip boundary assumption breaks down (Barrat and Bocquet 1999; Schoch et al. 2008; Vinogradova et al. 2009). As a result, the viscosity of water in the vicinity of the wall drops significantly (Wu et al. 2017; Vinogradova 1995). In fact, water viscosity in the vicinity of the wall is a function not only of wall material but also nanopore diameter (Hoang and Galliero 2012). When the nanopore diameter shrinks to a certain value, the diameter becomes the dominant factor influencing the water viscosity (Wu et al. 2017). In fact, the effect of varying viscosity on water transport in nanopores can be modeled by the continuum method (Wu et al. 2017).

The composition of the effective slip length and the relationship between the effective slip length and wall wettability is shown in Fig. 1. 


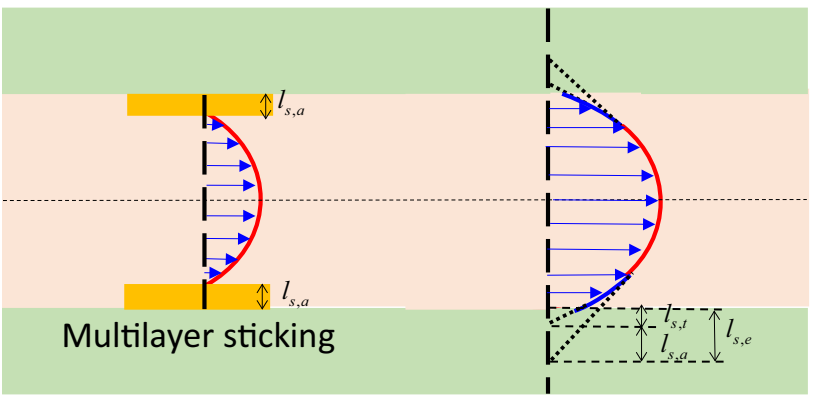

Fig. 1 Effective slip length $\left(l_{s, e}\right)$ versus wall wettability (Wu et al. 2017)

\section{Model description}

\section{Calculation of the true slip length}

The estimation of water transport behaviors in nanopores of shale formation depends on accurate calculation of the true slip length, which is defined as the ratio of the slip velocity to the shear rate at the effective hydrodynamic boundary position (Wu et al. 2017). For a majority of nanopores, there exists a relationship between the true slip length and the contact angle (Wu et al. 2017), which can be described as (Huang et al. 2008)

$l_{s, t}=\frac{C}{(\cos \theta+1)^{2}}$,

where $l_{s, t}$ denotes the true slip length of water on the nanopore wall of shale formation; $\theta$ denotes the contact angle, which is discussed in "Appendix A"; and $C$ is a fitting constant for a certain fluid-nanopore system obtained by experiments or molecular dynamic simulations (Wu et al. 2017), which is discussed in "Appendix B". What is worth to mention is that the constant $C$ should be fitted by the molecular dynamic simulations but the experimental results (Wu et al. 2017). This is because the experimental results are, in fact, the values of effective slip length, which is the function of a series of factors: wettability (Schmatko et al. 2005), surface roughness (Granick et al. 2003), nano-bubbles (Steinberger et al. 2007), operation methods (Thompson and Troian 1997), and the water viscosity (Doshi et al. 2005), but the true slip length (Wu et al. 2017). What is worth to stress is that Eq. (1) is obtained based on bulk liquid. Besides, it is observed by many researchers that the true slip length is the function of not only the contact angle, but also many other factors (Wu et al. 2017; Thompson and Robbins 1990; Joly et al. 2006a, b; Suk et al. 2008; Hilder et al. 2009; Ho et al. 2011; Tocci et al. 2014; Secchi et al. 2016).

\section{Viscosity equations}

Majumder et al. (2005) measured with experimental methods that the effective slip length of water transport in 7-nm aligned, multiwalled carbon nanotubes is up to $39-69 \mu \mathrm{m}$. Holt et al. (2006) published their research results that the effective slip length of water in 1.3-2.0 nm double-walled carbon nanotubes has reached $1.4 \mu \mathrm{m}$. Besides, the effective slip length can be a negative value when some water layers are stick to the wall due to strong hydrophilicity ( $\mathrm{Wu}$ et al. 2017; Chan and Horn 1985). In fact, large amount of molecular dynamic simulations (Hoang and Galliero 2012; Thomas and McGaughey 2008; Neek-Amal et al. 2016) and experiments (Ortiz-Young et al. 2013; Raviv et al. 2001) have pointed out that the value of water viscosity in the nanopores changes with space due to the interaction between water and the nanopore wall (Wu et al. 2017; Thomas and McGaughey 2007). The average viscosity of water (defined as the effective viscosity) in the nanopore can be calculated by the following equation (Wu et al. 2017; Thomas and McGaughey 2008):

$\mu(r)=\mu_{i} \frac{A_{i}(r)}{A_{t}(r)}+\mu_{\infty}\left[1-\frac{A_{i}(r)}{A_{t}(r)}\right]$,

where $\mu(r)$ represents the average viscosity of the water in the nanopore; $\mu_{i}$ and $\mu_{\infty}$ represent the water viscosity in the surface region and the bulk region, respectively; $A_{i}(r)$ and $A_{t}(r)$ represent the area of the surface region and entire section, respectively; and $r$ denotes the radius of the nanopore.

One can find that the calculated value of the effective viscosity depends on the area of the surface region, which is a function of the critical thickness. The critical thickness is defined as the value drawing the boundaries between the surface water and bulk water (Wu et al. 2017). Wu et al. (2017) adopted $0.7 \mathrm{~nm}$ as the value of critical thickness based on the spatial structure difference of water in nanopores by experiments and molecular dynamic simulations. When the diameter of the nanopore is larger than $1.6 \mathrm{~nm}$, the water viscosity in the surface region can be regarded as a function of the contact angle (Wu et al. 2017).

Based on the previous experiments and molecular dynamic simulations (Raviv et al. 2001; Thomas and McGaughey 2008; Kelly et al. 2015; Qin and Buehler 2015; Wei et al. 2014; Haria et al. 2013; Babu and Sathian 2011; Ye et al. 2011; Zhang et al. 2011; Petravic and Harrowell 2009; Chen et al. 2008; Liu et al. 2005), a quadratic equation is proposed to reveal the relationship between the viscosity ratio $\left(\mu_{i} / \mu_{\infty}\right)$ and contact angle, as shown in the following equation:

$\frac{\mu_{i}}{\mu_{\infty}}=0.00004 \theta^{2}-0.0273 \theta+3.4671$ 
Wu et al. (2017) proposed a linear equation to model the relationship between the viscosity ratio $\left(\mu_{i} / \mu_{\infty}\right)$ and contact angle. While their equation fitted well with experiments and molecular dynamic simulations, the linear relationship may neglect some underlining physics that is still not well understood at present. Therefore, a non-linear relationship is proposed to fit better with the coupled mechanisms.

It is observed from Eq. (3) that the water viscosity near the wall surface increases with decreasing contact angle. This is because the structure of hydrogen bonding network becomes strong with increasing interaction from nanopore wall (Qin and Buehler 2015). Besides, the water viscosity in the surface region can be larger or smaller than bulk water depending on hydrophilic (Kelly et al. 2015; Wei et al. 2014; Haria et al. 2013) or hydrophobic (Petravic and Harrowell 2009).

In fact, it has been pointed out that the water viscosity in the surface region is the function of not only contact angle, but also confinement (Wu et al. 2017). That is to say the water viscosity in the surface region will increase or decrease with decreasing diameter of hydrophilic or hydrophobic nanopore (Goertz et al. 2007; Petravic and Harrowell 2009; Chen et al. 2008). In fact, the water viscosity in the surface region can be 3-6 orders of magnitude higher than bulk water when the diameter of the hydrophilic nanopore is smaller than $1 \mathrm{~nm}$ (Ortiz-Young et al. 2013; Goertz et al. 2007), and it decreases rapidly with increasing diameter when the diameter is larger than $1 \mathrm{~nm}$ (Kelly et al. 2015). Furthermore, it has been pointed out that the water viscosity in the surface region can be regarded as the one element function of only contact angle when the diameter is larger than $1.4 \mathrm{~nm}$ (Wu et al. 2017). Therefore, equations obtained from experiments and molecu- equation for water transport in nanopores, as shown in the following equation (Holt et al. 2006):

$Q_{s}=\frac{\pi}{8 \mu_{\infty}}\left[\left(\frac{d}{2}\right)^{4}+4\left(\frac{d}{2}\right)^{3} l_{s, t}\right] \frac{\partial p}{\partial L}$.

Taking effective viscosity into consideration, Wu et al. (2017) proposed an improved equation for water transport in nanopores, as shown in the following equation (Wu et al. 2017):

$Q_{s}=\frac{\pi}{8 \mu(r)}\left[\left(\frac{d}{2}\right)^{4}+4\left(\frac{d}{2}\right)^{3} l_{s, t}\right] \frac{\partial p}{\partial L}$.

Majumder et al. (2005) and Holt et al. (2006) proposed a dimensionless physical quantity to describe the relative strength of water transport in nanopores: flow enhancement, which is defined as the ratio of the measured flow rate to $Q_{n}$, calculated by the Hagen-Poiseuille equation. Wu et al. (2017) tested the equation by comparing it with results from experiments (Holt et al. 2006; Majumder et al. 2005; Whitby et al. 2008; Secchi et al. 2016) and molecular dynamic simulations (Chiavazzo et al. 2014; Joseph and Aluru 2008; Thomas and McGaughey 2008, 2009; Babu and Sathian 2011; Milischuk and Ladanyi 2011) and there exists good agreement. The flow enhancement can be expressed as (Holt et al. 2006; Wu et al. 2017; Majumder et al. 2005)

$\varepsilon=\frac{Q_{s}}{Q_{n}}=\left[1+8 \frac{l_{s, t}}{d}\right] \frac{\mu_{\infty}}{\mu(r)}$.

Based on Eq. (1) (Huang et al. 2008), Eq. (2) (Wu et al. 2017; Thomas and McGaughey 2008) and Eq. (3), we can obtain

$\varepsilon=\left[1+8 \frac{C}{d(\cos \theta+1)^{2}}\right] \frac{A_{t}(d)}{A_{i}(d)\left(0.00004 \theta^{2}-0.0273 \theta+2.4671\right)+A_{t}(d)}$. lar dynamic simulations in Eq. (3) can only be used when the diameter of the nanopore is larger than $1.4 \mathrm{~nm}$ (Wu et al. 2017; Bocquet and Charlaix 2010).

\section{Transport model}

It has been pointed out that it is still effective to adopt the continuum method for modeling of water transport in nanopores when the diameter is larger than $1.6 \mathrm{~nm}$ (Wu et al. 2017; Striolo 2006; Thomas and McGaughey 2009). However, the non-slip Hagen-Poiseuille equation is no longer useful for water flow in nanopores due to slip flow or multilayer sticking at the surface condition (Holt et al. 2006; Wu et al. 2017; Majumder et al. 2005).

Taking slip flow into consideration, Holt et al. (2006) modified the Hagen-Poiseuille equation and proposed an analytical

\section{Discussion}

Figure 2 shows the relationship between flow enhancement and contact angle under various diameters of nanopores. It is observed that the flow enhancement is smaller than 1 when the contact angle is smaller than $100^{\circ}$ due to energy barrier induced by strong hydrophilicity of the nanopore wall (Carrasco et al. 2012). This physical law has also been summarized by Wu et al. (2017). However, their turning point of the contact angle is about $70^{\circ}$, which may be caused by their linear equation of the viscosity versus contact angle. Besides, the flow enhancement becomes infinite when the contact angle is approaching $180^{\circ}$, which is similar but different from $\mathrm{Wu}$ et al.'s (2017) results (limited value of seven orders of magnitude). The wider range of flow enhancement presented in this paper further demonstrates the strong effect of the interaction 


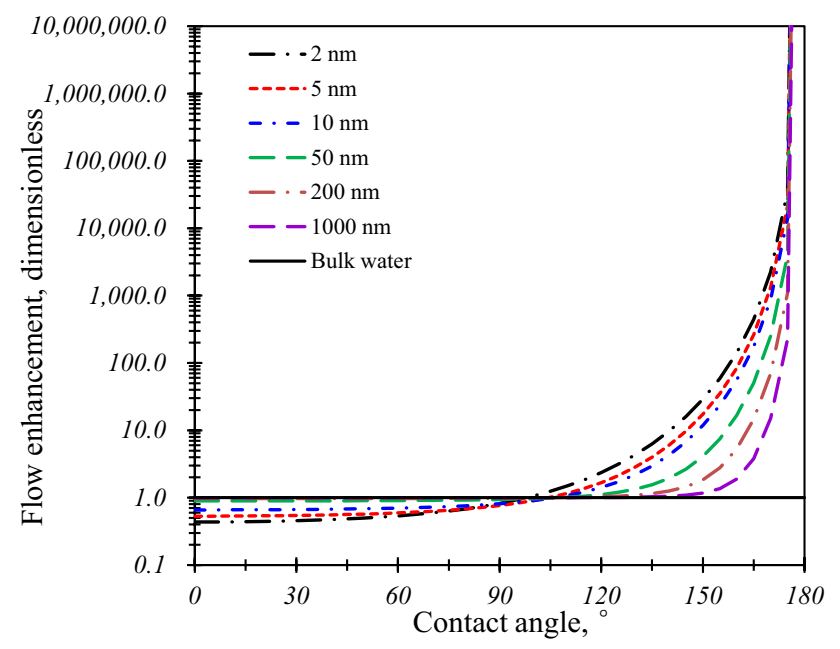

Fig. 2 Relationship between flow enhancement and contact angle under various diameters of nanopores (the reader can find the improvement of this figure from Wu et al.'s work (2017): the curves are moved in the horizontal direction due to calculation equation improvement)

from nanopore wall on the water flow in nanopores. These results further demonstrate the conclusion presented by $\mathrm{Wu}$ et al. (2017) that not only nano-bubbles (Granick et al. 2003; Choi and Kim 2006; Feuillebois et al. 2009) and frictionless walls (Whitby and Quirke 2007; Skoulidas et al. 2002), but also hydrophobic walls are able to enhance the transport capacity of water in nanopores. The effect of interaction between nanopore wall and water becomes stronger when the diameter shrinks (Wu et al. 2017; Koga et al. 2001). However, for a nanopore with diameter larger than $50 \mathrm{~nm}$, and the contact angle smaller than $150^{\circ}$, the enhanced flow is weak, which has also been detected in some experiments (Sinha et al. 2007). What is worth to mention is that the end effect also plays an important role in water flow in nanotubes, especially in relatively short nanotubes (Wu et al. 2017; Rossi et al. 2004; Glavatskiy and Bhatia 2016; Sisan and Lichter 2011).

In fact, the critical thickness ranges from 0.25 to $2.2 \mathrm{~nm}$ (Wu et al. 2017). Wu et al. (2017) adopted $0.7 \mathrm{~nm}$ as the critical thickness in their model. However, considering the complex mineral compositions in shale formation (Rimstidt et al. 2017; Alsleben et al. 2018), the critical thickness must not be a constant. In this model, the critical thickness can be obtained by molecular dynamic simulations of water transport in shale formation. The main conclusion of the work is that the flow enhancement increases with decreasing of critical thickness, especially for hydrophilic nanopores (the contact angle is smaller than $120^{\circ}$ ) and nanopores with a relatively small diameter (smaller than $50 \mathrm{~nm}$ ), as shown in Figs. 3 and 4.

Note that the fluid flow in nanopores of nanotube is completely different from fluid flow in a macropipe (Sun et al.

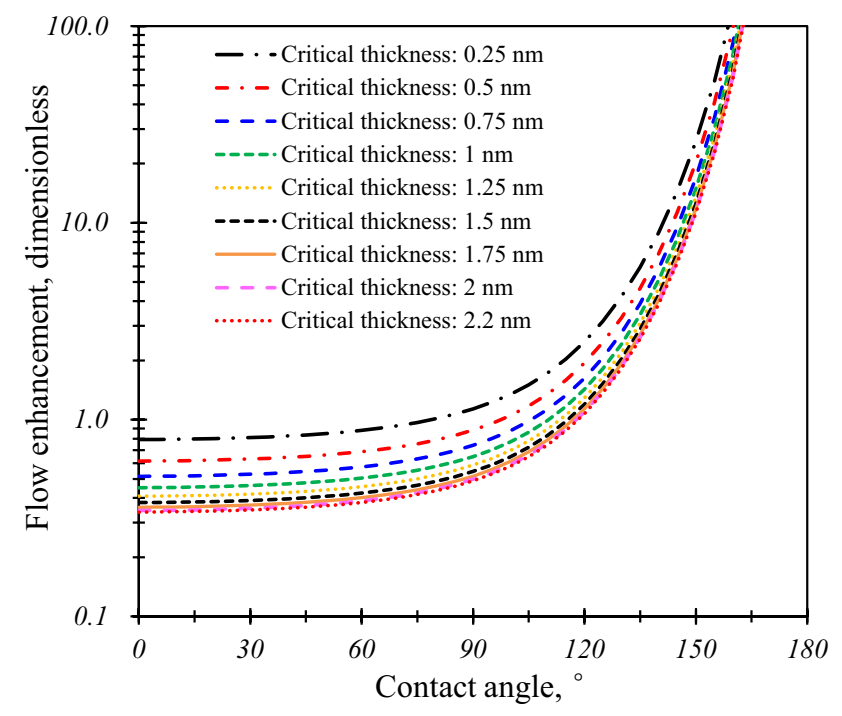

Fig. 3 Relationship between flow enhancement and contact angle under various critical thickness condition

2017f, 20181, m, n, o, p, q, r, s, t, u, v, w; Sheikholeslami 2017a, b, 2018a, b, b, d, e; Tang et al. 2018a, b; Tang and Wu 2018; Meng et al. 2018; Zhang et al. 2018a, b, c; Huang et al. 2018a, b, c). The authors have also conducted a series of studies of thermal fluid flow in wellbores during the thermal recovery process of heavy oil (Sun et al. 2017a, b, c, d, e, f, g, h, i, j, k, l, m, 2018a, b, c, d, e, f, g, h, i, j, k). The readers could find these works in the reference list to conduct a comparison for the difference of fluid flow in these two flow channels.

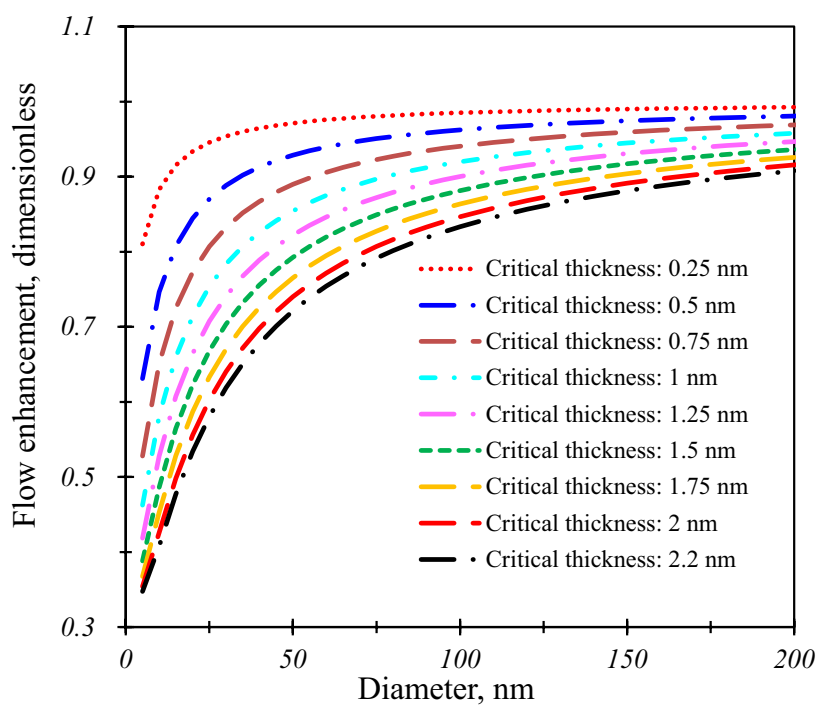

Fig. 4 Relationship between flow enhancement and diameter under various critical thickness condition

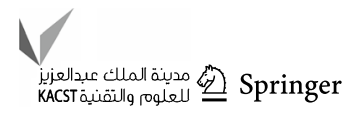




\section{Conclusions}

First of all, the authors appreciate $\mathrm{Wu}$ et al. for their great work and their summary of the previous works. What we have done is to move one step further based on Wu et al.'s work. In this paper, based on a comprehensive literature review, an improved model is proposed to investigate the flow of water in nanopores of shale formation. A quadratic equation is proposed to build the relationship between water viscosity and contact angle for nanopores with a diameter larger than $1.4 \mathrm{~nm}$. Then, the effect of critical thickness on water transport behaviors is discussed. Some meaningful conclusions are listed below:

a. The flow enhancement is smaller than 1 when the contact angle is smaller than $100^{\circ}$ due to energy barrier induced by strong hydrophilicity of the nanopore wall.

b. The flow enhancement becomes infinite when the contact angle is approaching $180^{\circ}$.

c. The flow enhancement increases with decreasing of critical thickness, especially for hydrophilic nanopores (the contact angle is smaller than $120^{\circ}$ ) and nanopores with a relatively small diameter (smaller than $50 \mathrm{~nm}$ ).

Acknowledgements First of all, the authors appreciate Wu et al. for their great work and their summary of previous works. What we have done is to move one step further based on Wu et al.'s work. The research was also supported by National Science and Technology Major Projects of China (Nos. 2016ZX05042, 2017ZX05039 and 2016ZX05039) and the National Natural Science Foundation Projects of China (Nos. 51504269, 51490654 and 40974055). The authors also acknowledge Science Foundation of China University of Petroleum, Beijing (No. C201605), the National Basic Research Program of China (2015CB250900), the Program for New Century Excellent Talents in University (Grant No. NCET-13-1030) to support part of this work.

Open Access This article is distributed under the terms of the Creative Commons Attribution 4.0 International License (http://creativeco mmons.org/licenses/by/4.0/), which permits unrestricted use, distribution, and reproduction in any medium, provided you give appropriate credit to the original author(s) and the source, provide a link to the Creative Commons license, and indicate if changes were made.

\section{Appendix A: contact angle calculation}

The interaction between water and nanopore wall can be expressed according to the Lorentz-Berthelot mixing rule ( $\mathrm{Wu}$ et al. 2017):

$\varepsilon_{\mathrm{SI}}=\sqrt{\varepsilon_{\mathrm{SS}} \varepsilon_{\mathrm{II}}} \quad(\mathrm{I}=O, H)$,

where $\varepsilon_{\mathrm{SI}}$ denotes the Lennard-Jones parameter, which represents the interaction between water and the nanopore wall; $\varepsilon_{\mathrm{SS}}$ represents the interaction between atoms of the shale formation; AND $\varepsilon_{\mathrm{II}}$ denotes the interaction between water molecules. Both $\varepsilon_{\mathrm{SS}}$ and $\varepsilon_{\mathrm{II}}$ can be obtained from molecular dynamic simulations (Wu et al. 2017).

The Lennard-Jones parameter is a function of the water monomer binding energy, which can be expressed as (Wu et al. 2017; Werder et al. 2003):

$\varepsilon_{\mathrm{SI}}=-0.0619 \Delta E$.

Furthermore, a relationship between the contact angle and the water monomer binding energy can be expressed as (Wu et al. 2017; Werder et al. 2003)

$\theta=185.8^{\circ}+\Delta E \cdot 14.5^{\circ}$.

Equation (1-3) can be used to calculate the contact angle of a water droplet on a wall with various physical and chemical properties (Wu et al. 2017).

\section{Appendix B: true slip length versus contact angle}

As mentioned in the text, the true slip length is small compared with effective length when the contact angle is relatively large (Wu et al. 2017). When $C$ in Eq. (a) is equal to 0.41 , the predicted results from Eq. (1) are in good agreement with the simulated results from molecular dynamic simulations (Wu et al. 2017; Cottin-Bizonne et al. 2003; Huang et al. 2008; Sendner et al. 2009; Nagayama and Cheng 2004; Barrat 1999). This is because the molecular dynamic simulation is able to build any ideal water-wall system, which is easy to avoid a lot of uncontrollable factors (e.g., smoothness of wall, adsorbed gases on walls or any other unknown contaminants) (Wu et al. 2017). As a result, the deviations of the simulated results from experiments are relatively large (Ortiz-Young et al. 2013; Wu et al. 2017; Xue et al. 2014; Bouzigues et al. 2008; Cottin-Bizonne et al. 2008, 2005; Maali et al. 2008; Honig and Ducker 2007; Joly et al. 2006; Cho et al. 2004; Vinogradova et al. 2001; Ahmad et al. 2015).

One may question the dependence of true slip length on contact angle. In fact, it has already been pointed out that the true slip length is depended on many factor, not only on the contact angle. Ho et al. (2011) pointed out that water molecules can slip on a wall with hydrophilic property due to preferential adsorption sites. When the preferential adsorption sites are close enough to each other, water molecules can jump from one adsorption site to another. The slip length on different walls may also vary significantly for a same contact angle (Tocci et al. 2014; Li and Zeng 2012). While these observations hold an objection point of view, there exists a relationship between the true slip length and contact angle for a majority of the water-wall systems (Cottin-Bizonne et al. 2002; Byun et al. 2008; Zhu et al. 2012). 


\section{References}

Ahmad K, Zhao X, Pan Y, Wang W, Huang Y (2015) Atomic force microscopy measurement of slip on smooth hydrophobic surfaces and possible artifacts. J Phys Chem C 119(22):12531-12537

Alfarge D, Wei M, Bai B (2018) Data analysis for $\mathrm{CO}_{2}$-EOR in shaleoil reservoirs based on a laboratory database. J Petrol Sci Eng 162:697-711

Alsleben H, Ameena F, Bufkin J, Chun J, Quarles CA (2018) Positron annihilation spectroscopy study of minerals commonly found in shale. Nucl Instrum Methods Phys Res Sect B 414:161-165

Aricò AS, Bruce P, Scrosati B, Tarascon JM, van Schalkwijk W (2005) Nanostructured materials for advanced energy conversion and storage devices. Nat Mater 4(5):366-377

Babu JS, Sathian SP (2011) The role of activation energy and reduced viscosity on the enhancement of water flow through carbon nanotubes. J Chem Phys 134(19):194509

Barrat JL (1999) Influence of wetting properties on hydrodynamic boundary conditions at a fluid/solid interface. Faraday Discuss 112:119-128

Barrat JL, Bocquet L (1999) Large slip effect at a nonwetting fluid-solid interface. Phys Rev Lett 82(23):4671

Bocquet L, Charlaix E (2010) Nanofluidics, from bulk to interfaces. Chem Soc Rev 39(3):1073-1095

Bouzigues CI, Tabeling P, Bocquet L (2008) Nanofluidics in the Debye layer at hydrophilic and hydrophobic surfaces. Phys Rev Lett 101(11):114503

Byun D, Kim J, Ko HS, Park HC (2008) Direct measurement of slip flows in superhydrophobic microchannels with transverse grooves. Phys Fluids 20(11):113601

Campbell SE, Luengo G, Srdanov VI, Wudl F, Israelachvili JN (1996) Very low viscosity at the solid-liquid interface induced by adsorbed C60 monolayers. Nature 382(6591):520-522

Carrasco J, Hodgson A, Michaelides A (2012) A molecular perspective of water at metal interfaces. Nat Mater 11(8):667-674

Chan DY, Horn RG (1985) The drainage of thin liquid films between solid surfaces. J Chem Phys 83(10):5311-5324

Chen X et al (2008) Nanoscale fluid transport: size and rate effects. Nano Lett 8(9):2988-2992

Chiavazzo E, Fasano M, Asinari P, Decuzzi P (2014) Scaling behaviour for the water transport in nanoconfined geometries. Nat Commun 5:4565

Cho JHJ, Law BM, Rieutord F (2004) Dipole-dependent slip of Newtonian liquids at smooth solid hydrophobic surfaces. Phys Rev Lett 92(16): 166102

Choi CH, Kim CJ (2006) Large slip of aqueous liquid flow over a nanoengineered superhydrophobic surface. Phys Rev Lett 96(6):066001

Cottin-Bizonne C, Jurine S, Baudry J, Crassous J, Restagno F, Charlaix E (2002) Nanorheology: an investigation of the boundary condition at hydrophobic and hydrophilic interfaces. Eur Phys J E 9(1):47-53

Cottin-Bizonne C, Barrat JL, Bocquet L, Charlaix E (2003) Lowfriction flows of liquid at nanopatterned interfaces. Nat Mater 2(4):237-240

Cottin-Bizonne C, Cross B, Steinberger A, Charlaix E (2005) Boundary slip on smooth hydrophobic surfaces: intrinsic effects and possible artifacts. Phys Rev Lett 94(5):056102

Cottin-Bizonne C, Steinberger A, Cross B, Raccurt O, Charlaix E (2008) Nanohydrodynamics: the intrinsic flow boundary condition on smooth surfaces. Langmuir 24(4):1165-1172

Doshi DA, Watkins EB, Israelachvili JN, Majewski J (2005) Reduced water density at hydrophobic surfaces: effect of dissolved gases. Proc Natl Acad Sci USA 102(27):9458-9462
Falk K, Coasne B, Pellenq R, Ulm FJ, Bocquet L (2015) Subcontinuum mass transport of condensed hydrocarbons in nanoporous media. Nat Commun 6:6949

Feibelman PJ (2013) Viscosity of ultrathin water films confined between aluminol surfaces of kaolinite: Ab initio simulations. J Phys Chem C 117(12):6088-6095

Feng D, Li X, Wang X, Li J, Sun F, Sun Z, Zhang T, Li P, Chen Y, Zhang X (2018a) Water adsorption and its impact on the pore structure characteristics of shale clay. Appl Clay Sci 155:126-138

Feng D, Li X, Wang X, Li J, Zhang X (2018b) Capillary filling under nanoconfinement: the relationship between effective viscosity and water-wall interactions. Int J Heat Mass Transf 118:900-910

Feuillebois F, Bazant MZ, Vinogradova OI (2009) Effective slip over superhydrophobic surfaces in thin channels. Phys Rev Lett 102(2):026001

Glavatskiy KS, Bhatia SK (2016) Thermodynamic resistance to matter flow at the interface of a porous membrane. Langmuir 32(14):3400-3411

Goertz MP, Houston JE, Zhu XY (2007) Hydrophilicity and the viscosity of interfacial water. Langmuir 23(10):5491-5497

Granick S (1991) Motions and relaxations of confined liquids. Science 253(5026): 1374-1379

Granick S, Zhu Y, Lee H (2003) Slippery questions about complex fluids flowing past solids. Nat Mater 2(4):221-227

Haria NR, Grest GS, Lorenz CD (2013) Viscosity of nanoconfined water between hydroxyl basal surfaces of kaolinite: classical simulation results. J Phys Chem C 117(12):6096-6104

Heinbuch U, Fischer J (1989) Liquid flow in pores: slip, no-slip, or multilayer sticking. Phys Rev A Gen Phys 40(2):1144-1146

Heuberger M, Zäch M, Spencer ND (2001) Density fluctuations under confinement: when is a fluid not a fluid? Science 292(5518):905-908

Hilder TA, Gordon D, Chung SH (2009) Salt rejection and water transport through boron nitride nanotubes. Small 5(19):2183-2190

Ho TA, Papavassiliou DV, Lee LL, Striolo A (2011) Liquid water can slip on a hydrophilic surface. Proc Natl Acad Sci USA 108(39):16170-16175

Hoang H, Galliero G (2012) Local viscosity of a fluid confined in a narrow pore. Phys Rev E Stat Nonlin Soft Matter Phys 86(2 Pt 1):021202

Holt JK et al (2006) Fast mass transport through sub-2-nanometer carbon nanotubes. Science 312(5776):1034-1037

Honig CD, Ducker WA (2007) No-slip hydrodynamic boundary condition for hydrophilic particles. Phys Rev Lett 98(2):028305

Huang DM, Sendner C, Horinek D, Netz RR, Bocquet L (2008) Water slippage versus contact angle: a quasiuniversal relationship. Phys Rev Lett 101(22):226101

Huang JY et al (2013) Nanowire liquid pumps. Nat Nanotechnol 8(4):277-281

Huang SJ, Cao M, Cheng LS (July 2018a) Experimental study on the mechanism of enhanced oil recovery by multi-thermal fluid in offshore heavy oil. Int J Heat Mass Transf 122:1074-1084

Huang SJ, Cao M, Cheng LS (2018b) Experimental study on aquathermolysis of different viscosity heavy oil with superheated steam. Energy Fuel 32(4):4850-4858

Huang SJ, Cao M, Xia Y, Chen X, Yang ML (2018c) Heat and mass transfer characteristics of steam in a horizontal wellbore with multi-point injection technique considering wellbore stock liquid. Int J Heat Mass Transf 127(Part B):949-958

Joly L, Ybert C, Trizac E, Bocquet L (2006a) Liquid friction on charged surfaces: from hydrodynamic slippage to electrokinetics. J Chem Phys 125(20):204716 
Joly L, Ybert C, Bocquet L (2006b) Probing the nanohydrodynamics at liquid-solid interfaces using thermal motion. Phys Rev Lett 96(4):046101

Joseph S, Aluru NR (2008) Why are carbon nanotubes fast transporters of water? Nano Lett 8(2):452-458

Karan S, Samitsu S, Peng X, Kurashima K, Ichinose I (2012) Ultrafast viscous permeation of organic solvents through diamond-like carbon nanosheets. Science 335(6067):444-447

Kelly S, Balhoff MT, Torres-Verdín C (2015) Quantification of bulk solution limits for liquid and interfacial transport in nanoconfinements. Langmuir 31(7):2167-2179

Keranen KM, Weingarten M, Abers GA, Bekins BA, Ge S (2014) Induced earthquakes. Sharp increase in central Oklahoma seismicity since 2008 induced by massive wastewater injection. Science 345(6195):448-451

Klein J, Kumacheva E (1995) Confinement-induced phase transitions in simple liquids. Science 269(5225):816-819

Köfinger J, Hummer G, Dellago C (2008) Macroscopically ordered water in nanopores. Proc Natl Acad Sci USA 105(36): 13218-13222

Koga K, Gao GT, Tanaka H, Zeng XC (2001) Formation of ordered ice nanotubes inside carbon nanotubes. Nature 412(6849):802-805

Krott LB, Bordin JR, Barbosa MC (2015) New structural anomaly induced by nanoconfinement. J Phys Chem B 119(1):291-300

Lasne D et al (2008) Velocity profiles of water flowing past solid glass surfaces using fluorescent nanoparticles and molecules as velocity probes. Phys Rev Lett 100(21):214502

Levinger NE (2002) Chemistry. Water in confinement. Science 298(5599): 1722-1723

Li H, Zeng XC (2012) Wetting and interfacial properties of water nanodroplets in contact with graphene and monolayer boron-nitride sheets. ACS nano 6(3):2401-2409

Li T, Gao J, Szoszkiewicz R, Landman U, Riedo E (2007) Structured and viscous water in subnanometer gaps. Phys Rev B 75(11): 115415

Liu Y, Wang Q, Zhang L, Wu T (2005a) Dynamics and density profile of water in nanotubes as one-dimensional fluid. Langmuir 21(25):12025-12030

Liu Y, Wang Q, Wu T, Zhang L (2005b) Fluid structure and transport properties of water inside carbon nanotubes. J Chem Phys 123(23):234701

Lorenz UJ, Zewail AH (2014) Nanofluidics. Observing liquid flow in nanotubes by 4D electron microscopy. Science 344(6191): 1496-1500

Ma $\mathrm{M}$ et al (2015) Water transport inside carbon nanotubes mediated by phononinduced oscillating friction. Nat Nanotechnol 10(8):692-695

Maali A, Cohen-Bouhacina T, Kellay H (2008) Measurement of the slip length of water flow on graphite surface. Appl Phys Lett 92(5):053101

Majumder M, Chopra N, Andrews R, Hinds BJ (2005) Nanoscale hydrodynamics: enhanced flow in carbon nanotubes. Nature 438(7064):44 (abstr)

Mashl RJ, Joseph S, Aluru NR, Jakobsson E (2003) Anomalously immobilized water: a new water phase induced by confinement in nanotubes. Nano Lett 3(5):589-592

Meng Y, Li X, Jiang M et al (2018) Experimental research on three dimensional flow characteristics of multiple horizontal fractures utilizing an innovative experiment apparatus. Arab J Geosci 11:243. https://doi.org/10.1007/s12517-018-3589-0

Milischuk AA, Ladanyi BM (2011) Structure and dynamics of water confined in silica nanopores. J Chem Phys 135(17):174709

Mirsaidov UM, Zheng H, Bhattacharya D, Casana Y, Matsudaira P (2012) Direct observation of stick-slip movements of water nanodroplets induced by an electron beam. Proc Natl Acad Sci USA 109(19):7187-7190
Monge M, Gil-Alana LA, de Gracia FP (2017) U.S. shale oil production and WTI prices behavior. Energy 141:12-19

Monteiro PJ, Rycroft CH, Barenblatt GI (2012) A mathematical model of fluid and gas flow in nanoporous media. Proc Natl Acad Sci USA 109(50):20309-20313

Nagayama G, Cheng P (2004) Effects of interface wettability on microscale flow by molecular dynamics simulation. Int J Heat Mass Transfer 47(3):501-513

Naguib N et al (2004) Observation of water confined in nanometer channels of closed carbon nanotubes. Nano Lett 4(11):2237-2243

Nair RR, Wu HA, Jayaram PN, Grigorieva IV, Geim AK (2012) Unimpeded permeation of water through helium-leak-tight graphenebased membranes. Science 335(6067):442-444

Neek-Amal M, Peeters FM, Grigorieva IV, Geim AK (2016) Commensurability effects in viscosity of nanoconfined water. ACS Nano 10(3):3685-3692

Neto C, Evans DR, Bonaccurso E, Butt HJ, Craig VS (2005) Boundary slip in Newtonian liquids: a review of experimental studies. Rep Prog Phys 68(12):2859

Ortiz-Young D, Chiu HC, Kim S, Voïtchovsky K, Riedo E (2013) The interplay between apparent viscosity and wettability in nanoconfined water. Nat Commun 4:2482

Petravic J, Harrowell P (2009) Spatial dependence of viscosity and thermal conductivity through a planar interface. J Phys Chem B 113(7):2059-2065

Qin Z, Buehler MJ (2015) Nonlinear viscous water at nanoporous twodimensional interfaces resists high-speed flow through cooperativity. Nano Lett 15(6):3939-3944

Raviv U, Laurat P, Klein J (2001) Fluidity of water confined to subnanometre films. Nature 413(6851):51-54

Rimstidt JD, Chermak JA, Schreiber ME (2017) Processes that control mineral and element abundances in shales. Earth Sci Rev 171:383-399

Rivera JL, McCabe C, Cummings PT (2002) Layering behavior and axial phase equilibria of pure water and water + carbon dioxide inside single wall carbon nanotubes. Nano Lett 2(12):1427-1431

Rossi MP et al (2004) Environmental scanning electron microscopy study of water in carbon nanopipes. Nano Lett 4(5):989-993

Sanhai WR, Sakamoto JH, Canady R, Ferrari M (2008) Seven challenges for nanomedicine. Nat Nanotechnol 3(5):242-244

Scatena LF, Brown MG, Richmond GL (2001) Water at hydrophobic surfaces: weak hydrogen bonding and strong orientation effects. Science 292(5518):908-912

Schmatko T, Hervet H, Leger L (2005) Friction and slip at simple fluid-solid interfaces: the roles of the molecular shape and the solid-liquid interaction. Phys Rev Lett 94(24):244501

Schoch RB, Han J, Renaud P (2008) Transport phenomena in nanofluidics. Rev Mod Phys 80(3):839-883

Secchi E et al (2016) Massive radius-dependent flow slippage in carbon nanotubes. Nature 537(7619):210-213

Sendner C, Horinek D, Bocquet L, Netz RR (2009) Interfacial water at hydrophobic and hydrophilic surfaces: slip, viscosity, and diffusion. Langmuir 25(18):10768-10781

Shannon MA et al (2008) Science and technology for water purification in the coming decades. Nature 452(7185):301-310

Sheikholeslami M (2017a) Lattice Boltzmann method simulation of MHD non-Darcy nanofluid free convection. Phys B 516:55-71

Sheikholeslami M (2017b) Influence of magnetic field on nanofluid free convection in an open porous cavity by means of Lattice Boltzmann Method. J Mol Liq 234:364-374

Sheikholeslami M (2018a) Numerical modeling of Nano enhanced PCM solidification in an enclosure with metallic fin. J Mol Liq 259:424-438

Sheikholeslami M (2018b) Numerical simulation for solidification in a LHTESS by means of Nano-enhanced PCM. J Taiwan Inst Chem Eng 86:25-41 
Sheikholeslami M (2018c) Solidification of NEPCM under the effect of magnetic field in a porous thermal energy storage enclosure using CuO nanoparticles. J Mol Liq 263:303-315

Sheikholeslami M (2018d) Finite element method for PCM solidification in existence of $\mathrm{CuO}$ nanoparticles. J Mol Liq 265:347-355

Sheikholeslami M (2018e) Numerical investigation of nanofluid free convection under the influence of electric field in a porous enclosure. J Mol Liq 249:1212-1221

Sinha S, Rossi MP, Mattia D, Gogotsi Y, Bau HH (2007) Induction and measurement of minute flow rates through nanopipes. Phys Fluids 19(1):013603

Siria A et al (2013) Giant osmotic energy conversion measured in a single transmembrane boron nitride nanotube. Nature 494(7438):455-458

Sisan TB, Lichter S (2011) The end of nanochannels. Microfluid Nanofluid 11(6):787-791

Skoulidas AI, Ackerman DM, Johnson JK, Sholl DS (2002) Rapid transport of gases in carbon nanotubes. Phys Rev Lett 89(18): 185901

Sparreboom W, van den Berg A, Eijkel JCT (2009) Principles and applications of nanofluidic transport. Nat Nanotechnol 4(11):713-720

Steinberger A, Cottin-Bizonne C, Kleimann P, Charlaix E (2007) High friction on a bubble mattress. Nat Mater 6(9):665-668

Striolo A (2006) The mechanism of water diffusion in narrow carbon nanotubes. Nano Lett 6(4):633-639

Suk ME, Raghunathan AV, Aluru NR (2008) Fast reverse osmosis using boron nitride and carbon nanotubes. Appl Phys Lett 92(13): 133120

Sun F, Yao Y, Li X (2017a) Effect analysis of non-condensable gases on superheated steam flow in vertical single-tubing steam injection pipes based on the real gas equation of state and the transient heat transfer model in formation. J Petrol Explor Product Technol. https://doi.org/10.1007/s13202-017-0419-y

Sun F, Yao Y, Li X, Zhao L (2017b) Type curve analysis of superheated steam flow in offshore horizontal wells. Int J Heat Mass Transf 113:850-860

Sun F, Yao Y, Li X, Yu P, Zhao L, Zhang Y (2017c) A numerical approach for obtaining type curves of superheated multi-component thermal fluid flow in concentric dual-tubing wells. Int J Heat Mass Transf 111:41-53

Sun F, Yao Y, Li X (2017d) Effect of gaseous $\mathrm{CO}_{2}$ on superheated steam flow in wells. Eng Sci Technol Int J 20(6):1579-1585

Sun F, Yao Y, Li X, Tian J, Zhu G, Chen Z (2017e) The flow and heat transfer characteristics of superheated steam in concentric dual-tubing wells. Int J Heat Mass Transf 115:1099-1108

Sun F, Yao Y, Li X, Yu P, Ding G, Zou M (2017f) The flow and heat transfer characteristics of superheated steam in offshore wells and analysis of superheated steam performance. Comput Chem Eng 100:80-93

Sun FR, Yao YD, Li XF et al (2017g) Forecast model for heating radius and productivity of horizontal wells with overheated steam soaking. Special Oil Gas Reservoir 24(2):120-124

Sun F, Yao Y, Li X, Li H, Chen G, Sun Z (2017h) A numerical study on the non-isothermal flow characteristics of superheated steam in ground pipelines and vertical wellbores. J Petrol Sci Eng 159:68-75

Sun FR, Yao YD, Li XF et al (2017i) An R-K-S equation-based study on the heat transmission features of multi-component thermal fluid injection through concentric dual-tubing. Petrol Drill Tech 45(2):107-114

Sun F, Yao Y, Li X, Zhao L, Ding G, Zhang X (2017j) The mass and heat transfer characteristics of superheated steam coupled with non-condensing gases in perforated horizontal wellbores. J Petrol Sci Eng 156:460-467
Sun F, Yao Y, Chen M, Li X, Zhao L, Meng Y, Sun Z, Zhang T, Feng D (2017k) Performance analysis of superheated steam injection for heavy oil recovery and modeling of wellbore heat efficiency. Energy 125:795-804

Sun FR, Yao YD, Li XF et al (20171) Characteristics of heat transfer in offshore wellbores with non-condensing gases flow coupled with overheated steam. Petrol Drill Tech 45(5):92-97

Sun FR, Yao YD, Li XF et al $(2017 \mathrm{~m})$ Flow characteristics of the parallel dual tube for superheated multi-component thermal fluid. Petrol Geol Oilfield Dev Daq 36(5):131-137

Sun F, Yao Y, Li G, Li X, Zhang T, Lu C, Liu W (2018a) An improved two-phase model for saturated steam flow in multipoint injection horizontal wells under steady-state injection condition. J Petrol Sci Eng 167:844-856

Sun F, Yao Y, Li G, Li X, Lu C, Chen Z (2018b) A model for predicting thermophysical properties of water at supercritical state in offshore CDTW. Measurement 124:241-251

Sun F, Yao Y, Li G, Li X, Chen M, Chen G, Zhang T (2018c) Analysis of superheated steam performance in offshore concentric dual-tubing wells. J Petrol Sci Eng 166:984-999

Sun F, Yao Y, Li X, Li G, Han S, Liu Q, Liu W (2018d) Type curve analysis of multi-phase flow of multi-component thermal fluid in toe-point injection horizontal wells considering phase change. J Petrol Sci Eng 165:557-566

Sun F, Yao Y, Li X, Li G, Liu Q, Han S, Zhou Y (2018e) Effect of friction work on key parameters of steam at different state in toe-point injection horizontal wellbores. J Petrol Sci Eng 164:655-662

Sun F, Yao Y, Li X, Li G, Huang L, Liu H, Chen Z, Liu Q, Liu W, Cao M, Han S (2018f) Exploitation of heavy oil by supercritical $\mathrm{CO}_{2}$ : effect analysis of supercritical $\mathrm{CO}_{2}$ on $\mathrm{H}_{2} \mathrm{O}$ at superheated state in integral joint tubing and annuli. Greenhouse Gas Sci Technol 8(3): 557-569

Sun F, Yao Y, Li X, Li G, Sun Z (2018g) A numerical model for predicting distributions of pressure and temperature of superheated steam in multi-point injection horizontal wells. Int $\mathrm{J}$ Heat Mass Transf 121:282-289

Sun F, Yao Y, Li G, Li X (2018h) Performance of geothermal energy extraction in a horizontal well by using $\mathrm{CO}_{2}$ as the working fluid. Energy Convers Manag 171:1529-1539

Sun F, Yao Y, Li X (2018i) Numerical simulation of superheated steam flow in dual-tubing wells. J Petrol Explor Product Technol 8(3):925-937. https://doi.org/10.1007/s13202-017-0390-7

Sun F, Yao Y, Li X (2018j) The heat and mass transfer characteristics of superheated steam in horizontal wells with toe-point injection technique. J Petrol Explor Product Technol. https://doi. org/10.1007/s13202-017-0407-2

Sun F, Yao Y, Li X, Li G (2018k) A brief communication on the effect of seawater on water flow in offshore wells at supercritical state. J Petrol Explor Product Technol. https://doi. org/10.1007/s13202-018-0456-1

Sun F, Yao Y, Li G, Li X (20181) Geothermal energy extraction in $\mathrm{CO}_{2}$ rich basin using abandoned horizontal wells. Energy 158:760-773

Sun F, Yao Y, Li X, Li G (2018m) An analytical equation for oil transport in nanopores of oil shale considering viscosity distribution. J Petrol Explor Product Technol. https://doi. org/10.1007/s13202-018-0486-8

Sun F, Yao Y, Li G (2018n) New analytical equations for productivity estimation of the cyclic $\mathrm{CO}_{2}$-assisted steam stimulation process considering the non-Newtonian percolation characteristics. J Petrol Explor Product Technol. https://doi.org/10.1007/ s13202-018-0518-4

Sun F, Yao Y, Li G, Li X, Li Q, Yang J, Wu J (2018o) A coupled model for $\mathrm{CO}_{2}$ and superheated steam flow in full-length concentric

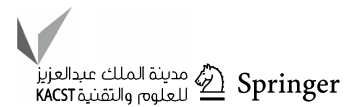


dual-tube horizontal wells to predict the thermophysical properties of $\mathrm{CO}_{2}$ and superheated steam mixture considering condensation. J Petrol Sci Eng 170:151-165

Sun F, Yao Y, Li X, Li G, Miao Y, Han S, Chen Z (2018p) Flow simulation of the mixture system of supercritical $\mathrm{CO}_{2} \&$ superheated steam in toe-point injection horizontal wellbores. J Petrol Sci Eng 163:199-210

Sun F, Yao Y, Li X, Li G, Chen Z, Chang Y, Cao M, Han S, Chaohui L, Feng D, Sun Z (2018q) Effect of Flowing seawater on supercritical $\mathrm{CO}_{2}$ - superheated water mixture flow in an offshore oil well considering the distribution of heat generated by the work of friction. J Petrol Sci Eng 162:460-468

Sun F, Yao Y, Li X (2018r) The heat and mass transfer characteristics of superheated steam coupled with non-condensing gases in horizontal wells with multi-point injection technique. Energy 143:995-1005

Sun F, Yao Y, Li G, Shiyuan Q, Zhang S, Shi Y, Xu Z, Li X (2018s) Effect of pressure and temperature of steam in parallel vertical injection wells on productivity of a horizontal well during the SAGD process: a numerical case study. SPE International Heavy Oil Conference \& Exhibition, SPE-193659-MS, 10-12 December 2018 in Kuwait City, Kuwait

Sun F, Yao Y, Li G, Xiangfang L (2018t) Effect of physical heating on productivity of cyclic superheated steam stimulation wells. J Petrol Explor Product Technol. https://doi.org/10.1007/s1320 2-018-0527-3

Sun F, Yao Y, Li G, Li X, Sun J (2018u) Comparison of steam front shape during steam flooding process under varying steam state condition: numerical analysis. Abu Dhabi International Petroleum Exhibition and Conference, SPE-192996-MS, 12-15 November, 2018, Abu Dhabi, UAE

Sun F, Yao Y, Li G, Feng N, Zhang S, Huang L, Li X (2018v) A numerical model for simulating supercritical water flow in perforated horizontal wellbores. SPE Kingdom of Saudi Arabia Annual Technical Symposium and Exhibition, SPE-KSA-, 23-26 April 2018 in Dammam, Saudi Arabia

Sun F, Yao Y, Li G, Zhao L, Liu H, Li X (2018w) Water performance in toe-point injection wellbores at supercritical state. In: SPE Trinidad and Tobago section energy resources conference, SPE191151-MS, 25-26 June 2018 in Port of Spain, Trinidad and Tobago. https://doi.org/10.2118/191151-MS

Surwade SP et al (2015) Water desalination using nanoporous singlelayer graphene. Nat Nanotechnol 10(5):459-464

Tan SH, Barton PI (2017) Optimal shale oil and gas investments in the United States. Energy 141:398-422

Tang J, Wu K (2018) A 3-D model for simulation of weak interface slippage for fracture height containment in shale reservoirs. Int J Solids Struct 144-145:248-264. https://doi.org/10.1016/j.ijsol str.2018.05.007

Tang J, Wu K, Zeng B, Huang H, Hu X, Guo X, Zuo L (2018a) Investigate effects of weak bedding interfaces on fracture geometry in unconventional reservoirs. J Petrol Sci Eng 165:992-1009. https ://doi.org/10.1016/j.petrol.2017.11.037

Tang J, Wu K, Li Y, Hu X, Liu Q, Ehlig-Economides C (2018b) Numerical investigation of the interactions between hydraulic fracture and bedding planes with non-orthogonal approach angle. Eng Fract Mech 200:1-16

Thomas JA, McGaughey AJH (2007) Effect of surface wettability on liquid density, structure, and diffusion near a solid surface. J Chem Phys 126(3):034707

Thomas JA, McGaughey AJ (2008) Reassessing fast water transport through carbon nanotubes. Nano Lett 8(9):2788-2793

Thomas JA, McGaughey AJ (2009) Water flow in carbon nanotubes: transition to subcontinuum transport. Phys Rev Lett 102(18): 184502
Thompson PA, Robbins MO (1990) Origin of stick-slip motion in boundary lubrication. Science 250(4982):792-794

Thompson PA, Troian SM (1997) A general boundary condition for liquid flow at solid surfaces. Nature 389(6649):360-362

Tocci G, Joly L, Michaelides A (2014) Friction of water on graphene and hexagonal boron nitride from ab initio methods: very different slippage despite very similar interface structures. Nano Lett 14(12):6872-6877

Verweij H, Schillo MC, Li J (2007) Fast mass transport through carbon nanotube membranes. Small 3(12):1996-2004

Vinogradova OI (1995) Drainage of a thin liquid film confined between hydrophobic surfaces. Langmuir 11(6):2213-2220

Vinogradova OI, Butt HJ, Yakubov GE, Feuillebois F (2001) Dynamic effects on force measurements. I. Viscous drag on the atomic force microscope cantilever. Rev Sci Instrum 72(5):2330-2339

Vinogradova OI, Koynov K, Best A, Feuillebois F (2009) Direct measurements of hydrophobic slippage using double-focus fluorescence cross-correlation. Phys Rev Lett 102(11):118302

Warner NR et al (2012) Geochemical evidence for possible natural migration of Marcellus Formation brine to shallow aquifers in Pennsylvania. Proc Natl Acad Sci USA 109(30): 11961-11966

Wei N, Peng X, Xu Z (2014) Breakdown of fast water transport in graphene oxides. Phys Rev E Stat Nonlin Soft Matter Phys 89(1):012113

Werder T et al (2001) Molecular dynamics simulation of contact angles of water droplets in carbon nanotubes. Nano Lett 1(12):697-702

Werder T, Walther JH, Jaffe RL, Halicioglu T, Koumoutsakos P (2003) On the water-carbon interaction for use in molecular dynamics simulations of graphite and carbon nanotubes. J Phys Chem B 107(6):1345-1352

Whitby M, Quirke N (2007) Fluid flow in carbon nanotubes and nanopipes. Nat Nanotechnol 2(2):87-94

Whitby M, Cagnon L, Thanou M, Quirke N (2008) Enhanced fluid flow through nanoscale carbon pipes. Nano Lett 8(9):2632-2637

Wu K, Chen Z, Li J, Li X, Xu J, Dong X (2017) Wettability effect on nanoconfined water flow. Proc Natl Acad Sci USA 114(13):3358-3363

Xue $Y$ et al (2014) How solid-liquid adhesive property regulates liquid slippage on solid surfaces? Langmuir 31(1):226-232

Ye H, Zhang H, Zhang Z, Zheng Y (2011) Size and temperature effects on the viscosity of water inside carbon nanotubes. Nanoscale Res Lett 6(1):87

Yu X, Luo Z, Li H, Gan D (2018) Effect of vibration on the separation efficiency of oil shale in a compound dry separator. Fuel 214:242-253

Zhang H, Ye H, Zheng Y, Zhang Z (2011) Prediction of the viscosity of water confined in carbon nanotubes. Microfluid Nanofluid 10(2):403-414

Zhang T, Li X, Li J, Feng D, Li P, Zhang Z, Chen Y, Wang S (2017a) Numerical investigation of the well shut-in and fracture uncertainty on fluid-loss and production performance in gas-shale reservoirs. J Nat Gas Sci Eng 46:421-435

Zhang T, Li X, Sun Z, Feng D, Miao Y, Li P, Zhang Z (2017b) An analytical model for relative permeability in water-wet nanoporous media. Chem Eng Sci 174:1-12

Zhang S, Huang Z, Wang H, Zhang H, Zhang C, Xiong C (2018a) Thermal characteristics analysis with local thermal non-equilibrium model during liquid nitrogen jet fracturing for HDR reservoirs. Appl Therm Eng 143:482-492

Zhang S, Huang Z, Huang P, Wu X, Xiong C, Zhang C (2018b) Numerical and experimental analysis of hot dry rock fracturing 
stimulation with high-pressure abrasive liquid nitrogen jet. J Petrol Sci Eng 163:156-165

Zhang SK, Huang ZW, Li GS, Wu XG, Peng C, Zhang WP (2018c) Numerical analysis of transient conjugate heat transfer and thermal stress distribution in geothermal drilling with high-pressure liquid nitrogen jet. Appl Therm Eng 129:1348-1357 25
Zhu L, Attard P, Neto C (2012) Reconciling slip measurements in symmetric and asymmetric systems. Langmuir 28(20):7768-7774

Publisher's Note Springer Nature remains neutral with regard to jurisdictional claims in published maps and institutional affiliations 